\title{
Prognosis and treatment of FOLFOX therapy related interstitial pneumonia: a plea for multimodal immune modulating therapy in the respiratory insufficient patient
}

Annick De Weerdt ${ }^{* *}$, Amélie Dendooven², Annemie Snoeckx ${ }^{3}$, Jan Pen ${ }^{4}$, Martin Lammens ${ }^{2}$ and Philippe G. Jorens ${ }^{1}$

\begin{abstract}
Background: The FOLFOX regimen, i.e., folinic acid (FOL), fluorouracil (F) and oxaliplatin (OX), is a drug cocktail that is used to treat gastric and colorectal cancers. Despite the concomitant improvements in response rate, duration of response and patient survival, reports of serious toxic pulmonary side effects have progressively emerged.

Case presentation: We describe a patient who was treated with FOLFOX as an adjuvant to a rectosigmoidal resection of a rectosigmoidal carcinoma and who developed respiratory insufficiency requiring mechanical ventilation. Computed tomography (CT) imaging and open lung biopsy findings were compatible with interstitial pneumonia (IP). She received multimodal combination treatment (acetylcysteine, corticosteroids, immune globulins and cyclophosphamide) and survived. We performed a systematic literature search and reviewed all 45 reported cases of FOLFOX-related lung toxicity and/or pulmonary fibrosis for their clinical characteristics and their outcomes related to therapy.

Conclusions: We found that for the 45 cases with available data, the median age was 70 years, and the male-female ratio was 3.5: 1. In the patients exhibiting only mild respiratory symptoms, discontinuation of the culprit drug (oxaliplatin) resulted in a $100 \%$ regression of the symptoms. However the prognosis of the respiratory insufficient patient proved to be grim: death occurred in $76.9 \%$ of the cases despite conventional treatment with corticosteroids. We therefore urge oncologists and critical care specialists not to limit their interventions to the discontinuation of chemotherapy, artificial ventilation, corticosteroids and glutathione replenishment and to consider the gradual introduction of additional immune-modulating agents whenever life-threatening respiratory symptoms in oxaliplatin-treated patients do not subside; all the more so considering the fact that our analysis showed that every patient who survived intubation and mechanical ventilation experienced a full clinical recovery.
\end{abstract}

Keywords: FOLFOX, Oxaliplatin toxicity, Chemotherapy lung, Interstitial lung disease, Interstitial pneumonia, Drug induced pulmonary toxicity, Immune globulins, Cyclophosphamide, Case report and review

\footnotetext{
*Correspondence: Annick.de.weerdt@uza.be

'Department of Intensive Care Medicine, Antwerp University Hospital,

University of Antwerp, Wilrijkstraat 10, 2650 Edegem, Belgium

Full list of author information is available at the end of the article
} 


\section{Background}

Since the middle of the previous century, 5fluorouracil (5-FU) has been the cornerstone in the treatment of colorectal cancer. The initial addition of folinic acid (leucovorin) and subsequent addition of oxaliplatin (OX) resulted in improved response rates, longer remissions and an increase in patient survival $[1,2]$. Subsequently, the combination of folinic acid, 5-fluorouracil and oxaliplatin, i.e., the so-called FOLFOX regimen, became a well-established treatment for colorectal malignancy either as in monotherapy or as an adjuvant to surgery [1]. With the widespread use of this triple chemotherapeutic combination therapy, reports of increased toxicity (e.g., peripheral neuropathy, neutropenia, thrombocytopenia, vomiting) compared with the 5-FU/leucovorin treatment emerged [3]. Additionally, interstitial lung disease has been reported. In the majority of cases, the noxious pulmonary effects occur rather late in the course of therapy [4-9], although there have been exceptions to this rule [10-14]. Although pulmonary toxicity in conjunction with FOLFOX therapy is uncommon ( $\leq$ $1.5 \%$ [15], it can be lethal despite the immediate discontinuation of the chemotherapeutic drugs and the initiation of immunotherapy (i.e., corticosteroids). Indirect arguments designating oxaliplatin as the causative pulmonary toxic agent can be found in more than one publication $[4,7,12,14,16-19]$.

We describe a patient with profound pulmonary toxicity secondary to FOLFOX who was successfully treated with a combination of acetylcysteine, corticosteroids, immune globulins and cyclophosphamide. Additionally we reviewed all other reports of similar cases.

\section{Case presentation}

A 49-year-old non-smoking female patient, who received a diagnosis of rectosigmoidal carcinoma 4 months prior and was treated with (laparoscopic) rectosigmoidal resection and adjuvant FOLFOX chemotherapy, was admitted to the hospital due to progressive dyspnoea approximately 3 weeks after the sixth chemotherapy session. CT examination of the lungs revealed extensive abnormalities in both lungs with diffuse ground glass abnormalities in both the upper (Fig. 1a) and lower lobes (Fig. 1b) and areas of consolidation at the level of the lower lobes (Fig. 1b). Antibiotics were empirically prescribed (moxifloxacin) from day one. Hypoxic respiratory insufficiency arose and necessitated intubation 1 week after admission. Immediately thereafter, she was referred to our university hospital. On admission to our intensive care unit (ICU), 70\% oxygen (PEEP $8 \mathrm{~cm} \mathrm{H} \mathrm{H}_{2} \mathrm{O}$ ) was needed to prevent frank hypoxemia. The serum white blood cell count amounted to $19 \times 10^{9} / \mathrm{L}$ (the normal value is up to $\left.10 \times 10^{9} / \mathrm{L}\right)$. Predominantly, neutrophils $\left(78.8 \%, 14.97 \times 10^{9} / \mathrm{L}\right)$ and to a lesser extent lymphocytes $\left(16.3 \%, 3.10 \times 10^{9} / \mathrm{L}\right)$, were present. There was no peripheral eosinophilia. The Creactive protein (CRP) level was low $(1.2 \mathrm{mg} / \mathrm{dl})$, and there were no biochemical signs of other organ failure (i.e., serum creatinine $0.55 \mathrm{mg} / \mathrm{dl}$ ).
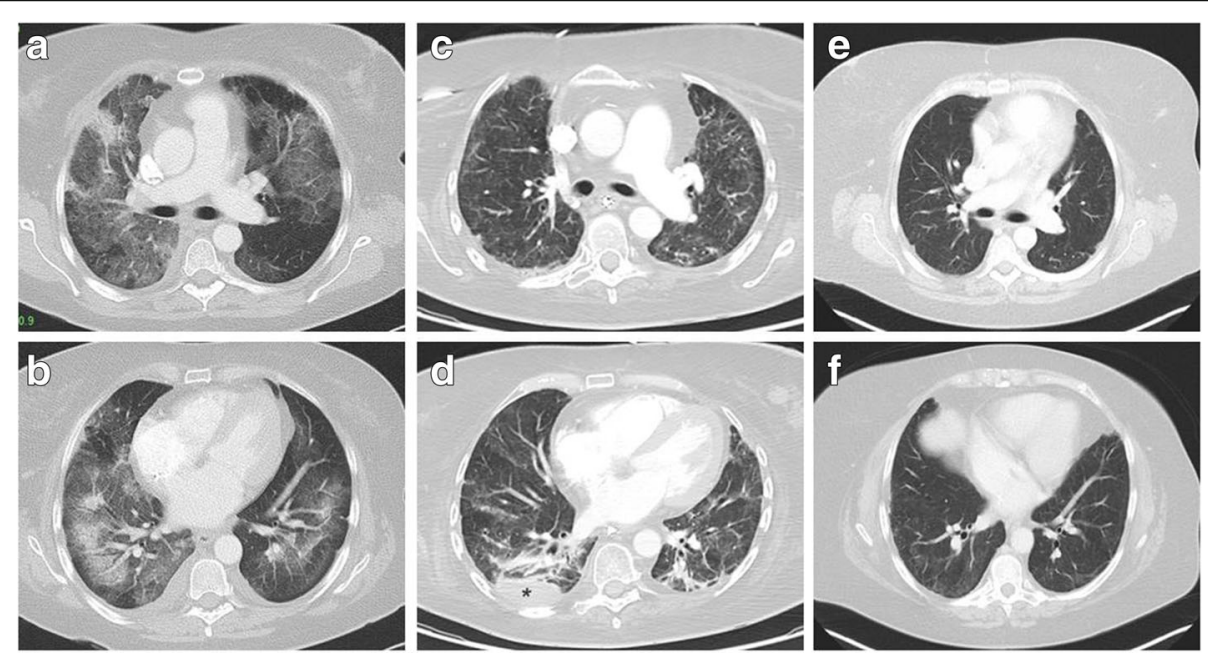

Fig. 1 axial CT images of the chest in the lung window setting at the levels of the upper lobes (images in a, c and e) and the lower lobes (images in b, $d$ and f). CT examination at the time of diagnosis revealed extensive abnormalities in both lungs with diffuse ground glass abnormalities in both the upper (a) and lower lobes (b). Associated areas of consolidation at the lower lobe level were present. Follow-up images 11 weeks after multimodal therapy for ILD revealed a good resolution of the ground glass abnormalities and consolidation with only minor parenchymal changes in the upper lobes, some small foci of ground glass abnormalities and some parenchymal bands (c). In the lower lobes, the nodular area (d asterisk) was consistent with loculated postoperative fluid due to the open-lung biopsy. The most recent examination more than 4 years after the event (e, f) showed no abnormalities 
Shortly after admittance to our ICU, a bronchoalveolar lavage (BAL) was performed in the right middle lobe and revealed a white blood cell count of $44 / \mathrm{m}^{3}$ that mostly consisted of neutrophils (90\%) in addition to $4 \%$ lymphocytes, 6\% macrophages and no eosinophils, which suggested infectious lung disease or acute diffuse lung injury [20]. However, no microorganisms (e.g., (myco)bacteria, moulds, fungi, or viruses (entero-, rhino-, parainfluenza, adeno-, herpes simplex, or cytomegalovirus)) were detected. PCR on the BAL fluid for herpes simplex, cytomegalovirus, Epstein-Barr virus, Chlamydia pneumoniae, Mycoplasma pneumoniae and Bordetella pertussis also proved negative. Additional histopathological examination of the lavage liquid did not reveal malignant cells. There was no family history of interstitial lung disease (ILD), and there were no coexisting medical conditions that favoured the development of ILD. Moreover, there had been no occupational exposure to pulmonary toxins and no prior use of potential ILD-causing drugs (e.g., bleomycin, busulphan, gemcitabine, mitomycin, paclitaxel, docetaxel, nitrofurantoin, amiodarone), with the exception of the FOLFOX chemotherapy.

Given the proof of the absence of pulmonary infection, at $48 \mathrm{~h}$ after admission, high-dose corticosteroids (methylprednisolone $4 \times 250 \mathrm{mg}$ per day) were administered intravenously (IV) over 5 consecutive days followed by a tapering scheme. This therapy was initiated while considering the possibility of an autoimmune disease or chemotherapy-related pulmonary toxicity [21]. Meanwhile, IV acetylcysteine (1800 mg per day) had been administered from day one in our hospital with the initial intention of preventing contrast-induced nephropathy in this CT-scanned patient.

In view of the fact that screening for autoimmune and systemic diseases (e.g., anti-nuclear antibodies, antineutrophil cytoplasmatic antibodies, complement factors, circulating immune complexes, lupus anticoagulant, immune globulin dosage, retinal fundoscopy) revealed no aberrations, and based on the absence of a favourable respiratory evolution after 14 days of therapy, a surgical (open) lung biopsy (right middle lobe) and a tracheotomy were performed.

An initial quick examination of the lung biopsy fragments revealed an interstitial pattern of disease with widening of the alveolar septa. While awaiting further microscopic characterization, immune globulins (Sandoglobulin $0.4 \mathrm{~g} / \mathrm{kg}$ ) were administered intravenously during a five-day period in an attempt to reduce the pulmonary inflammation that led to fibrosis [22-24]. Approximately a fortnight later, a single dose of cyclophosphamide $(10.5 \mathrm{mg} / \mathrm{kg}=1000 \mathrm{mg}$, Endoxan, Baxter, Braine-1-Alleud Walloon Brabant, Lessines Hainaut, Belgium) was administered due to the persistent need for ventilatory support and the possibility of an unspecified immunological process. The intravenous administration of acetylcysteine was continued. After these therapeutic interventions, the oxygen demand gradually fell. The definite histopathological findings validated the presence of on-going damage of the alveolar epithelium with evolving pulmonary fibrosis. Thickened alveolar septa with lymphocytic inflammatory infiltrate and fibrosis and an exudate in the alveolar lumina lined with reactive cuboid pneumocytes were present. There were no arguments for concomitant vasculitis, infection or malignancy (Fig. 2).

The interstitial pattern on chest X-ray and follow-up CT gradually dissolved. A follow-up CT-scan 13 weeks after admittance to our ICU revealed a good resolution of the ground glass abnormalities and consolidation with only minor residual parenchymal changes in the upper lobes (Fig. 1c).

The patient remained dependent upon mechanical ventilation until day 80 due to intercurrent ventilatorassociated pulmonary infections that were treated with broad-spectrum antibiotics, acute bilateral pulmonary embolism, critical illness myopathy (secondary to the glucocorticoid treatment) and polyneuropathy (electromyographically confirmed), all of which contributed to the general neuromuscular weakness and failure to wean from mechanical ventilation.

On day 101, she was referred to the department of respiratory medicine for further care still receiving oral methylprednisolone at a dosage of $20 \mathrm{mg}$ per day and acetylcysteine in a daily dosage of $1200 \mathrm{mg}$.

She left the hospital 8 months after admission and resumed work 1 year after discharge. She remained under medical supervision and, in a diagnostic work up for evolving carcinoembryonic antigen, underwent computed tomography of the lungs more than 4 years later. No residual pulmonary abnormalities were found (Fig. 1 e-f).

\section{Methods}

A systematic literature search was performed in PubMed for all publications (case reports and case series) regarding FOLFOX-related pulmonary toxicity with or without pulmonary fibrosis, respiratory insufficiency, intubation and artificial ventilation. To reduce/eliminate the chance of bias, we excluded all reported cases that were not treated solely with FOLFOX (e.g., FOLFOX/bevacizumab) or not solely attributable to FOLFOX. The corresponding authors of the reports that did not mention the ventilation or intubation statuses of their patients were contacted by e-mail or telephone to provide this information because it was our aim to describe and compare treatment strategies in the dramatic cases, i.e., the respiratory insufficient, intubated patients. Forty-five cases were identified $[4-19,25-39]$. The data were 

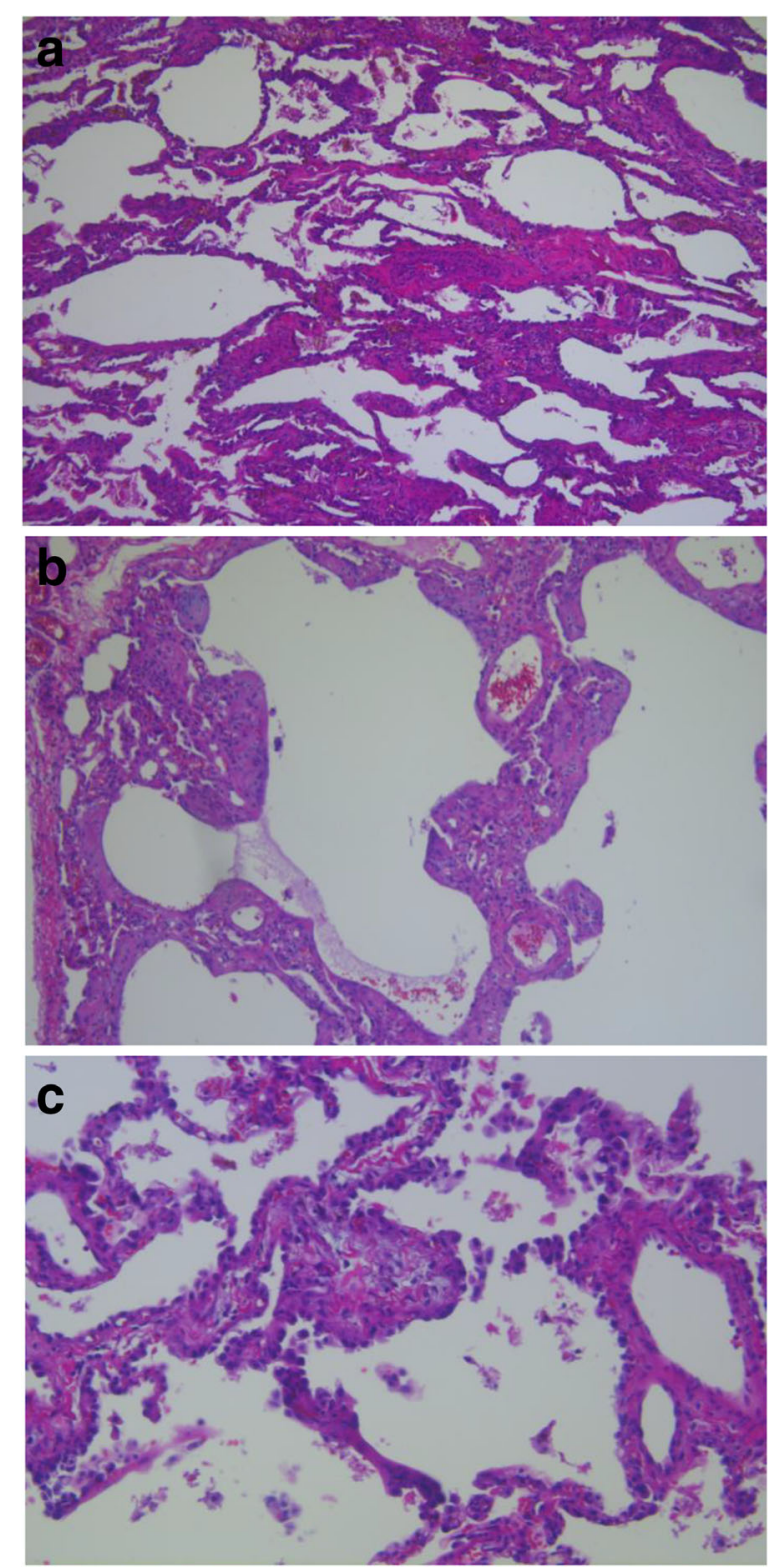

Fig. 2 lung tissue (day 14, open-lung biopsy, staining Hematoxylin Eosin) exhibiting a pattern compatible with on-going damage of the alveolar epithelium with evolving pulmonary fibrosis. a magnification 37x: histology (wedge biopsy) revealing lung tissue with a disturbed architecture. The alveolar septa are thickened in a non-specific interstitial pneumonia (NSIP) pattern with lymphocytic inflammatory infiltrate and fibrosis. b magnification 185x: the alveolar lumina exhibit the presence of an exudate. c Magnification 380x: reactive cuboid pneumocytes line the alveolar lumina. This picture is consistent with interstitial pneumonitis

analyzed using Student's t-tests. Values of $p<0.05$ were considered statistically significant.

\section{Results}

Interstitial lung disease associated with FOLFOX therapy seems to be a global problem. Physicians on nearly every continent (Table 1) have published reports regarding this topic. Including our own, there are currently 45 reports about FOLFOX-related pulmonary toxicity, including 18 from Asia, 16 from Europe, 5 from North America, 3 from South America and 3 from Oceania.

An overview of all of the reported FOLFOX-related pulmonary disease cases (Table 1) revealed that there seems to be an overwhelming male preponderance (male (M) $35 / 45=77,8 \%$; female (F) $10 / 45=22,2 \%$ ). Although the overall incidence of digestive cancer is higher in men [40-42], the incidence of oxaliplatin-related nonpulmonary toxic symptoms (e.g., neurotoxicity) is higher in women [43], which thus leaves the question of a possible increase in male gender-related pulmonary toxicity unresolved.

The mean age of all patients who developed pulmonary toxicity was 67.6 years $(\mathrm{Y})$, with mean ages of $68.7 \mathrm{Y}$ for the males and $63.9 \mathrm{Y}$ for the women.

On average, ILD attributable to FOLFOX occurred after a median of 8 cycles of FOLFOX therapy (range 122 cycles) and a mean dose of $729.8 \mathrm{mg} / \mathrm{m}^{2}$ OX (range $85-1200 \mathrm{mg} / \mathrm{m}^{2}$, median $700 \mathrm{mg} / \mathrm{m}^{2}$ ). The men who developed pulmonary toxicity did so after a mean of 8.2 therapy cycles (range 1-22 cycles, median 8 cycles) and a mean OX dose of $738.3 \mathrm{mg} / \mathrm{m}^{2}$ (range $85-1716 \mathrm{mg} /$ $\mathrm{m}^{2}$, median $732.5 \mathrm{mg} / \mathrm{m}^{2}$ ). The women who developed ILD did so after a mean of 7.6 cycles (range 2-12 cycles, median 7 cycles) and a mean OX dose of $701 \mathrm{mg} / \mathrm{m}^{2}$ (range 170-1200 mg/m², median $630 \mathrm{mg} / \mathrm{m}^{2}$ ). These differences in mean age, number of cycles and mean dose were not significant between the men and women (all Ps $>0.5$ ).

Five of the 45 patients (11.1\%) with evidence of ILD on imaging studies received no other therapy other than the discontinuation of FOLFOX. These patients only exhibited mild symptoms (Table 2). None of these patients died. The other 40 patients $(40 / 45=88.9 \%)$ with more marked symptoms were treated with corticosteroids, and $36(36 / 40=90 \%)$ of these patients were treated with corticosteroids as a monotherapy $(36 / 45=80 \%$ of the total study population). Twenty of the 36 patients treated with corticosteroids as monotherapy (55.6\%) exhibited improvement, and 16 (44.4\%) of these patients died.

In the group of patients who exhibited improvement after treatment with corticosteroids as monotherapy, the mean number of FOLFOX therapy cycles was 6.95 (range 1-12 cycles, median 7 cycles). These patients had been treated with a mean OX dose of $630.35 \mathrm{mg} / \mathrm{m}^{2}$ (range $85-1200 \mathrm{mg} / \mathrm{m}^{2}$, median $690 \mathrm{mg} / \mathrm{m}^{2}$ ). Despite the fact that steroids have a much shorter half life in women than in men [44], five of the 7 female patients (71.4\%) who were treated with corticosteroids as monotherapy exhibited improvement as opposed to only 15 of the 29 male patients (51.7\%). This difference might be 


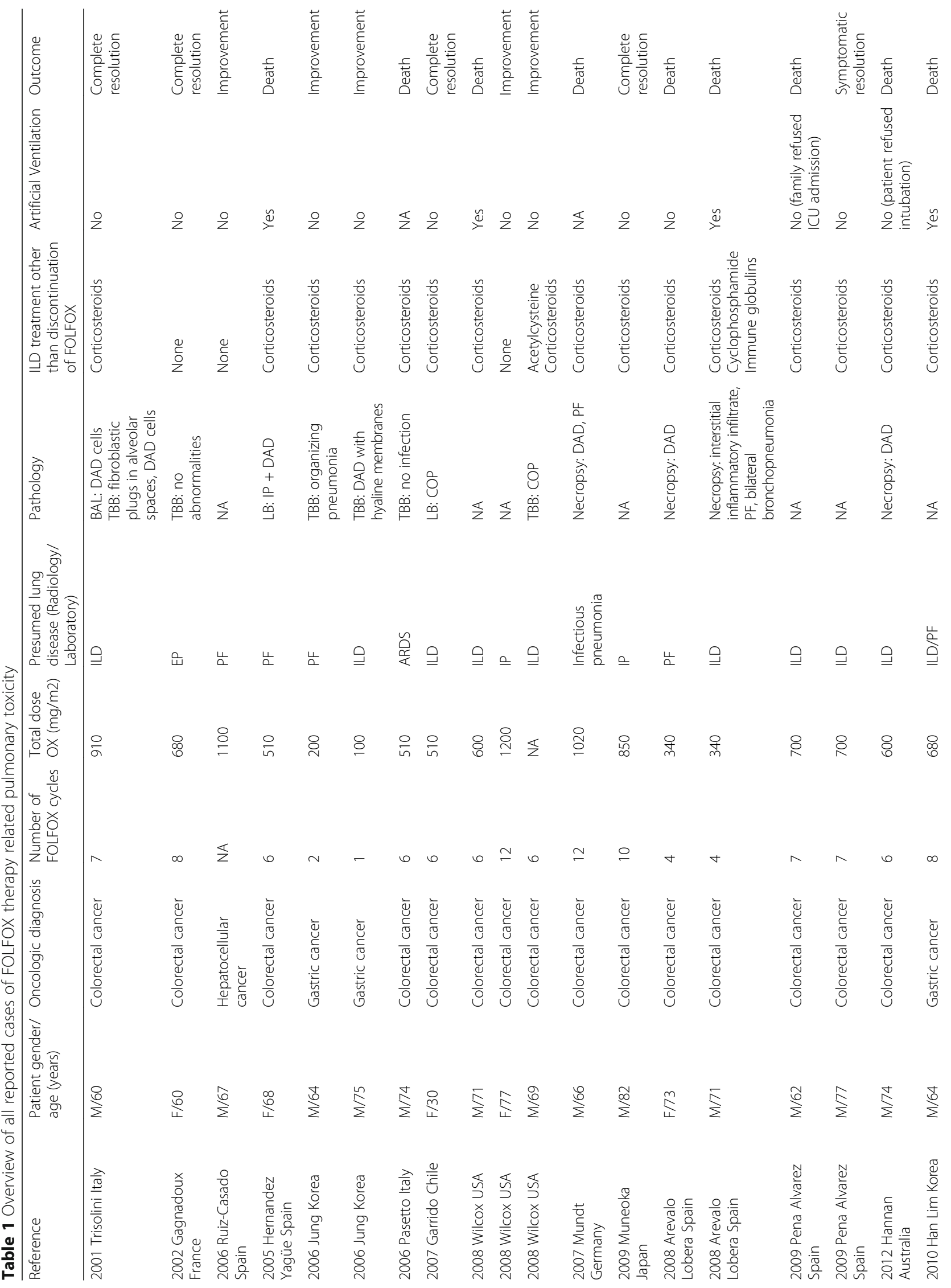




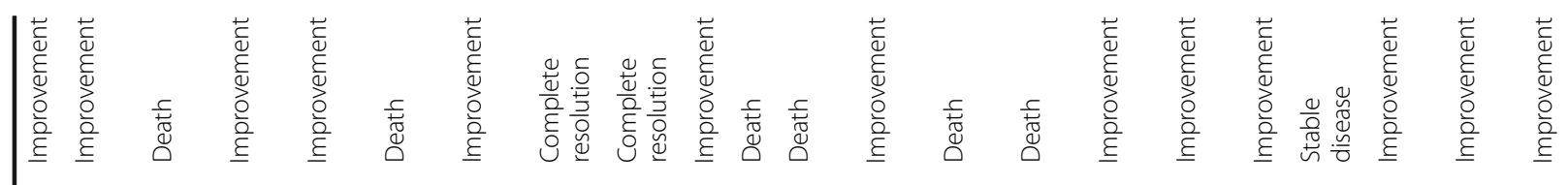

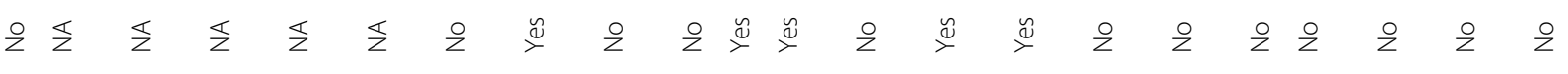

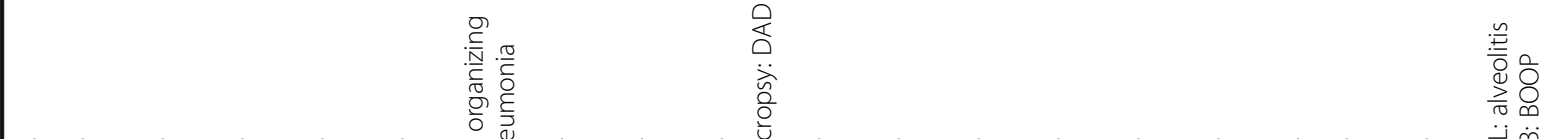

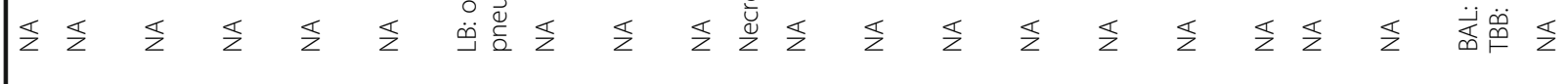

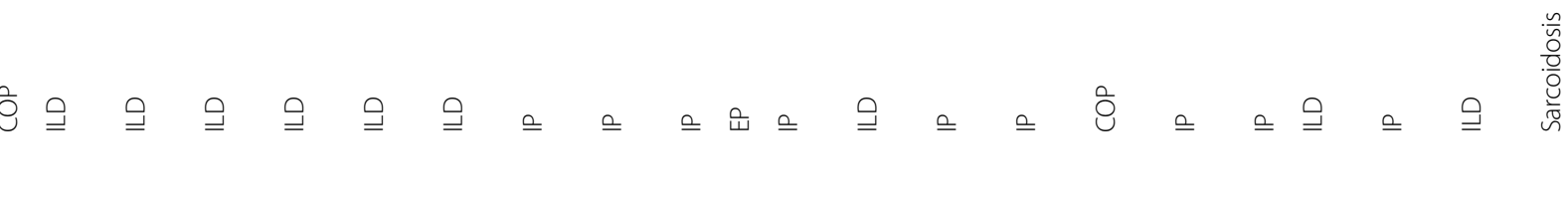

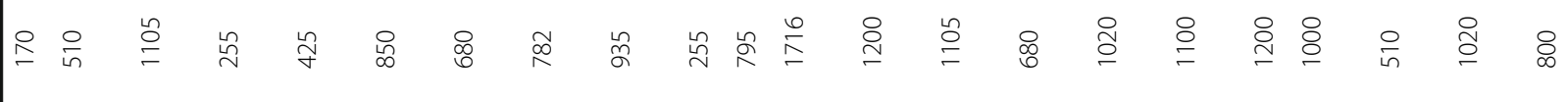

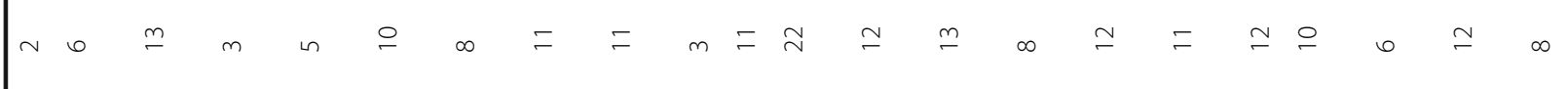

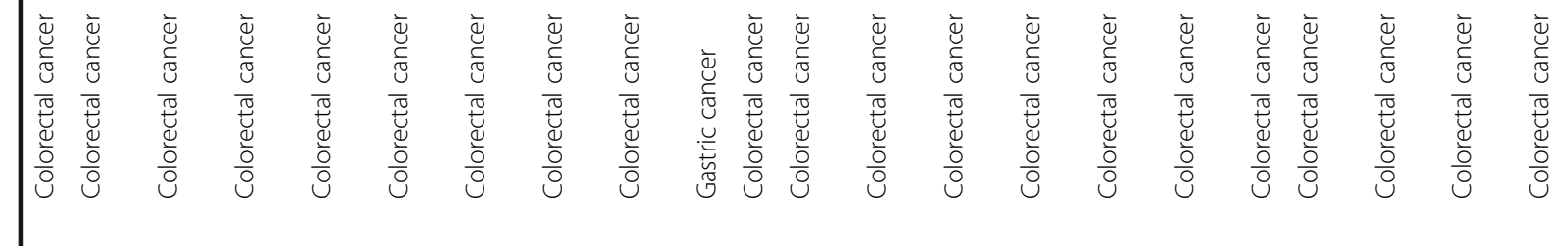

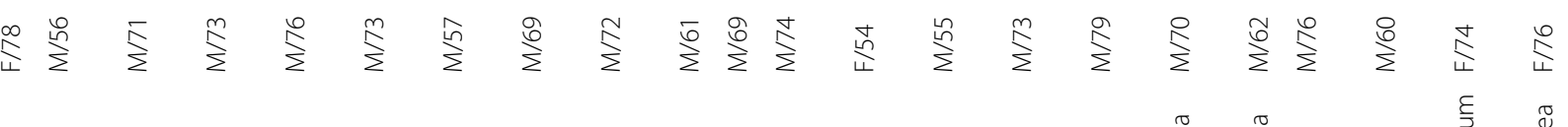

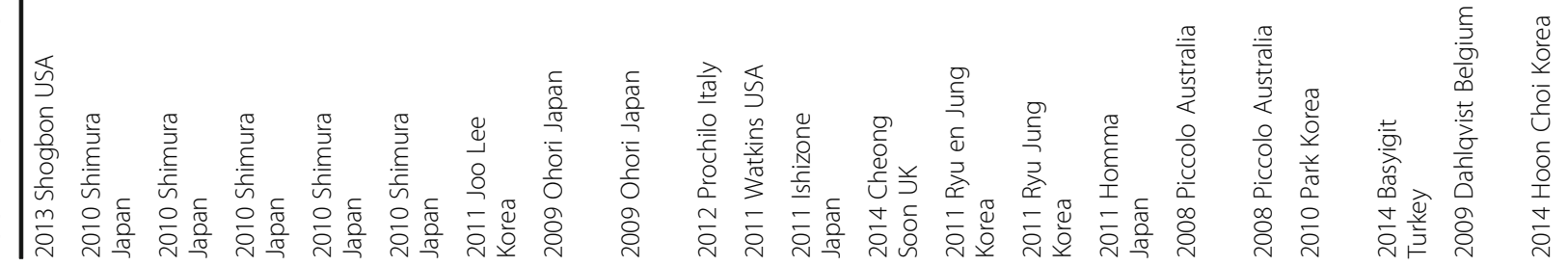




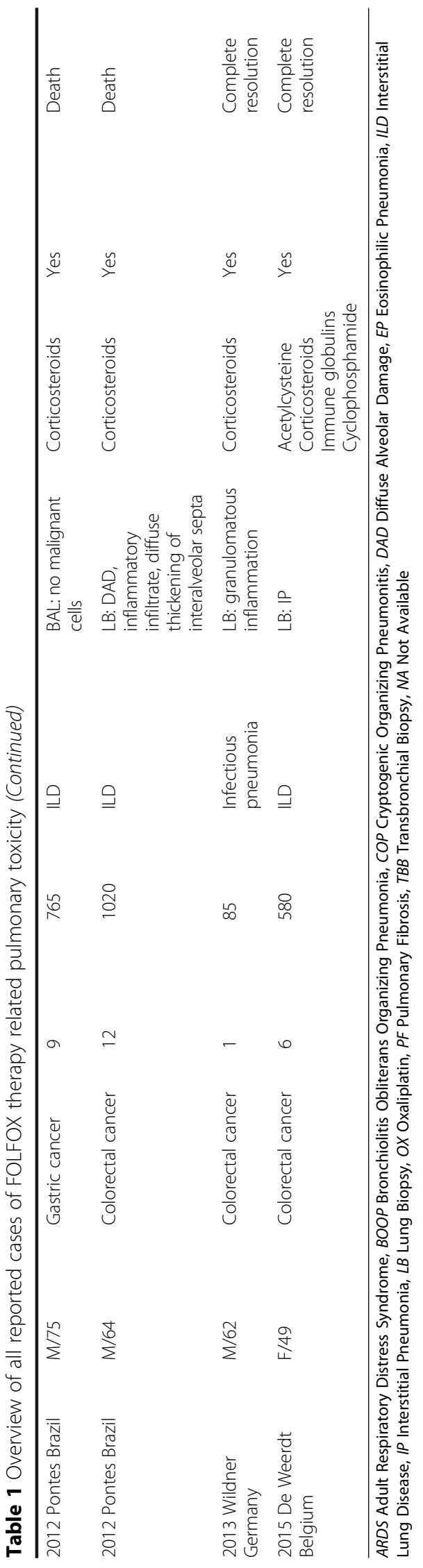


Table 2 Clinical characteristics of patients with FOLFOX therapy related pulmonary disease treated with discontinuation of chemotherapy

\begin{tabular}{|c|c|c|c|c|c|c|}
\hline Reference & $\begin{array}{l}\text { Patient } \\
\text { Gender/Age }\end{array}$ & $\begin{array}{l}\text { Preexisting lung disease with the } \\
\text { exception of lung metastasis }\end{array}$ & Smoking & Symptomes & $\begin{array}{l}\text { Oxygen } \\
\text { supplement }\end{array}$ & $\begin{array}{l}\text { Pulmonary } \\
\text { function tests }\end{array}$ \\
\hline Gagnadoux & $\mathrm{F} / 60$ & None & No & $\begin{array}{l}\text { Cough, progressive } \\
\text { dyspnea on exertion }\end{array}$ & None & $\begin{array}{l}\text { FEV1 } 1.980 \mathrm{~L}(90 \%) \\
\text { TLC } 4.207 \mathrm{~L}(90 \%) \\
\text { DLCo } 4.4 \mathrm{ml} / \mathrm{mmHg} / \\
\min (59 \%)\end{array}$ \\
\hline Ruiz Casado & M/67 & $\begin{array}{l}C T \text { : some signs of pulmonary } \\
\text { fibrosis in the basal portions }\end{array}$ & NA & None & None & NA \\
\hline Wilcox & $F / 77$ & None & No & $\begin{array}{l}\text { Dry cough, dyspnea } \\
\text { on exertion }\end{array}$ & None & $\begin{array}{l}\text { Normal lung volumes } \\
\mathrm{DL} \mathrm{L}_{\mathrm{co}} 9.3 \mathrm{ml} / \mathrm{mmHg} / \\
\mathrm{min}(54 \%)\end{array}$ \\
\hline Park & M/76 & Bronchial asthma & $\begin{array}{l}\text { Ex-smoker } 40 \\
\text { pack years }\end{array}$ & $\begin{array}{l}\text { General systemic } \\
\text { weakness, loss } \\
\text { of appetite }\end{array}$ & None & $\begin{array}{l}\text { FVC } 2.26 \mathrm{~L}(95 \%) \\
\text { FEV } 11.46 \mathrm{~L}(92 \%) \\
\mathrm{DL}_{\mathrm{CO}} 10,8 \mathrm{ml} / \mathrm{min} / \\
\mathrm{mmHg}(109 \%)\end{array}$ \\
\hline Basyigit & $\mathrm{M} / 60$ & None & $\begin{array}{l}\text { Ex-smoker } 14 \\
\text { pack years }\end{array}$ & Dyspnea on exertion & None & NA \\
\hline
\end{tabular}

explained by the fact that females exhibit a greater sensitivity to corticosteroids [44].

The patients who died in this group had received a mean 9.56 cycles of therapy (range 4-22, median 8.5 cycles) and a mean OX dose of $812.25 \mathrm{mg} / \mathrm{m}^{2}$ (median $732.5 \mathrm{mg} / \mathrm{m}^{2}$ ).

Three of the $4(75 \%)$ patients who were treated with a multimodal therapy regimen exhibited improvement. One patient was treated with a combination of corticosteroids and acetylcysteine, another was treated with a combination of corticosteroids and cyclophosphamide. One patient who was treated with a combination of corticosteroids, cyclophosphamide and immune globulins died. Prior to the FOLFOX treatment, he was diagnosed with Wegener's disease with lung involvement, which probably contributed to the severity of the progression of ILD and his demise [10]. Our own patient was treated with a combination of corticosteroids, acetylcysteine, immune globulins and cyclophosphamide and exhibited improvement.

Information regarding intubation or not was available for 38 of the 45 patients $(84.4 \%)$. Twenty-five of these patients did not receive mechanical ventilation $(25 / 38=65.8 \%): 23$ of them did not require it $(23 /$ $25=92 \%)$, two of them were not intubated due to patient or family refusal.

The patients who were intubated had been treated with a mean OX dose of $742.92 \mathrm{mg} / \mathrm{m}^{2}$ (range $85-$ $1716 \mathrm{mg} / \mathrm{m}^{2}$, median $680 \mathrm{mg} / \mathrm{m}^{2}$ ). The patients who were not intubated had been treated with a mean OX dose of $740.83 \mathrm{mg} / \mathrm{m}^{2}$ (range $100-1200 \mathrm{mg} / \mathrm{m}^{2}$, median $\left.750 \mathrm{mg} / \mathrm{m}^{2}\right)$.

Ten of the 13 patients $(10 / 13=76.9 \%)$ who were intubated died. They had been treated with a mean OX dose of $821.10 \mathrm{mg} / \mathrm{m}^{2}$ (range $340-1716 \mathrm{mg} / \mathrm{m}^{2}$, median $722.5 \mathrm{mg} / \mathrm{m}^{2}$ ). The intubated patients who survived had received a mean OX dose of $482.33 \mathrm{mg} / \mathrm{m}^{2}$ (range $85-$ $782 \mathrm{mg} / \mathrm{m}^{2}$, median $580 \mathrm{mg} / \mathrm{m}^{2}$ ).

Nine of the 10 intubated patients who died (90\%) were treated with corticosteroids as monotherapy. The tenth intubated patient who died was the one with Wegener's disease.

Two of the intubated patients who survived (2/ $3=66.67 \%$ ) were treated with corticosteroids as monotherapy. The third patient who survived was our patient and was treated with acetylcysteine, corticosteroids, immune globulins and cyclophosphamide. All of the patients who had been intubated and survived developed complete resolution of their respiratory symptoms.

Seventeen out of the $45(37.8 \%)$ patients died. The patients who died had been treated (mean of 9.24 episodes) with a mean dose of OX dose of $784.47 \mathrm{mg} / \mathrm{m}^{2}$ (range $340-1716 \mathrm{mg} / \mathrm{m}^{2}$, median $700 \mathrm{mg} / \mathrm{m}^{2}$ ). The patients who survived had received a mean OX dose of $695.44 \mathrm{mg} / \mathrm{m}^{2}$ (range $85-1200 \mathrm{mg} / \mathrm{m}^{2}$, median $700 \mathrm{mg} / \mathrm{m}^{2}$ ) over a mean of 7 therapy cycles. Again, these differences were not significant.

In summary, we found that the discontinuation of the precipitating drug resulted in a $100 \%$ regression of the symptoms in the patients whose respiration was not too strongly affected, and we demonstrated that intubation heralded death in the majority of cases even with corticosteroid treatment.

\section{Discussion}

Interstitial lung disease has diverse origins (e.g., autoimmune or systemic disease, exposure to drugs or herbs, infection, radiation, inhaled organic and inorganic substances, the late phase of the adult respiratory distress syndrome, cryptogenic) $[45,46]$ and often leads to death.

The diagnosis of a drug-induced lung disorder is considered when diagnostic algorithms have excluded all 
other potential aetiologies and when a distinct temporal association between exposure to the drug(s) and the development of respiratory complaints can be established [47]. In our patient, the respiratory symptoms arose after the 6th chemotherapy session, were rapidly progressive in nature, and were without microbial, autoimmune or environmental explanation. No infectious causes triggering the clinical picture were identified, although the high neutrophil count in the bronchoalveolar lavage fluid was initially strongly suggestive of microbial disease. In retrospect, we found that this finding was also compatible with drug-induced lung disease [20]. In view of the fact that an autoimmune disease could not be diagnosed, the administration of FOLFOX was considered to be the probable and most plausible cause of the biopsy-proven interstitial pneumonitis. Similar histological findings have been reported in three other cases of FOLFOXrelated ILD [10, 32, 39].

To which of the three components of the FOLFOX regimen should the development of ILD be attributed? Thus far, there have been no reports linking folinic acid (leucovorin) in monotherapy to pulmonary toxicity. Five-fluorouracil is a thymidilate synthase inhibitor whose antimetabolite properties are enhanced by folates. It is one of the most frequently used chemotherapeutic agents and is applied in mono- and combined therapy for various solid malignancies of the head, neck, breast, lungs, gastrointestinal tract, prostate and bladder. Known side effects include alopecia, stomatitis, emesis, coronary spasms, hand-foot syndrome, diarrhoea and myelosuppression $[48,49]$. There has only been one (Japanese) report of pulmonary toxicity accompanying the administration of 5-FU as monotherapy [50]. Oxaliplatin is a third-generation platinum derivative (diaminocyclohexane, containing platinum) that blocks DNA replication and transcription through the induction of intrastrand or interstrand lesions and DNA protein cross links [51]. Oxaliplatin is active against breast, gastric and colon cancers, renal cell carcinoma, sarcoma and cisplatin-resistant cell lines and tumour models including lung, ovarian, cervix, colon and leukaemia cell lines [51]. Known side effects include alopecia, peripheral sensory neuropathy (limb dysesthesia or paresthesia), haematological abnormalities (anaemia, thrombocytopenia, neutropenia), electrolyte disturbances (hyponatraemia, kalaemia), hepatocellular injury, nausea and vomiting, ototoxicity and laryngeal dysesthesia [6, 52, 53]. An important indirect argument pointing in the direction of oxaliplatin as "the" pulmonary toxicity-inducing culprit lies in the observation that respiratory symptoms present during FOLFOX therapy do not recur after rechallenge with a 5-FU- and leucovorin-containing but oxaliplatin-deprived chemotherapy cocktail $[4,7,12,14,16-19]$.
When ILD is thought to be secondary to a chemical insult, discontinuation of the causative agent should be the first therapeutic intervention. Although sufficient for some, not all patients will experience improvement or full recovery after the cessation of the culprit compound. In our patient, the FOLFOX administration had already been discontinued, and acetylcysteine (supplying glutathione) was administered from day one in our hospital. Given that arguments linking oxaliplatin administration to glutathione depletion exist $[30,32]$, it seemed logical to continue glutathione supplementation because this molecule plays an important role in protecting the lungs against oxidative damage, which is a possible and probable contributing factor to the emergence of interstitial pneumonitis and subsequent evolution to pulmonary fibrosis.

Accounting for the severity of the illness, corticosteroid therapy, which is a well-established therapy modality, was initiated shortly after disease onset. Because no favourable respiratory evolution over a 14-day steroid course was observed, and no autoimmune disease had been diagnosed in the meantime, intravenous immune globulins (IVIgs) were given in an attempt to reduce the deposition of excessive amounts of extracellular proteins (particularly collagen-I) in the lung and thus prohibit the progression of the lung fibrosis already observed in the patient's lung biopsy. These IVIgs were administered over a five-day period. The rationale for this treatment was found in experimental data that indicated that IVIgs are capable of preventing and treating bleomycininduced pulmonary fibrosis in mice through the reduced expression of collagen-I protein in the affected lungs $[23,24]$. Postulated mechanisms of this anti-fibrotic action of IVIg include modulation of cytokine production, inhibition of the complement reaction and inhibition of the CD95 receptor (Fas) activity through the presence of anti-Fas antibodies in IVIg [23, 54, 55]. Subsequently, one dose of cyclophosphamide, a nitrogen mustard alkylating and lymphocyte-modulating agent, was administered. This immunosuppressive steroid-sparing agent is used to treat autoimmune inflammatory disorders and associated interstitial lung disease and is frequently added to corticosteroid therapy to enhance the clinical response due to the additional suppression of immunoreactions that cause lung damage [56]. In our patient, an intravenous pulse was administered because at that moment, an unspecified immunological process (possibly with vasculitis) leading to pulmonary fibrosis seemed possible.

In our analysis of the 45 reported cases of FOLFOXrelated pulmonary disease, we found that the administered treatments were variable in terms of the drugs used and highly variable in terms of the durations and dosages of the corticosteroids used. Hence, it was 
impossible to determine the exact contribution of each individual drug or drug dosage to the recoveries of the patients. Moreover, in some patients, ILD regression was observed without special treatment but "merely" after discontinuation of FOLFOX. The fact that our patient exhibited no improvement after the withdrawal of the causative agent and developed a full clinical and radiographic recovery after the introduction of acetylcysteine, corticosteroids, immune globulins and cyclophosphamide, led us to believe that a causal relationship between this multimodal therapy and respiratory progress exists.

Considering the frequency with which FOLFOX therapy is used worldwide, the reported incidence of ILD seems extremely low. We wondered why this is. Are not all cases of FOLFOX related pulmonary toxicity reported, or are only a small number of people genetically or otherwise predisposed? Are there age, gender, ethnic or geographical differences in the concentrations of innate NO, glutathione or profibrotic agents (e.g., type 2 CD4-positive lymphocytes, CD40 receptor and ligand interactions, interleukin-4, interleukin-10, interleukin13, Th3-type cytokine-transforming growth factor beta 1 , and platelet-derived growth factor) [22-24] that contribute to the development of pulmonary toxicity? Could there be interindividual differences in oxaliplatin metabolism that lead to toxicity? Indeed, the biotransformation of oxaliplatin leads to the formation of aquated platinum forms in the blood. Three compounds can be found: total platinum, free (ultrafiltrable) platinum, and erythrocyte platinum [57]. Platinum is rapidly cleared from the plasma by renal elimination. However, what if the erythrocyte platinum is not as harmless as generally accepted but rather exhibits toxic effects in isolated cases, and what if the clearance of erythrocyte platinum is delayed in a minority of patients?

\section{Conclusions}

FOLFOX therapy related pulmonary toxicity is uncommon but often lethal in respiratory insufficient patients. We urge oncologists and critical care physicians not to limit their interventions to the discontinuation of chemotherapy, artificial ventilation, corticosteroid therapy and glutathione replenishment and to consider the gradual introduction of additional immune-modulating agents (e.g., immune globulins and cyclophosphamide) whenever life-threatening respiratory symptoms in oxaliplatin-treated patients do not subside.

\section{Abbreviations}

5 - FU: 5-fluorouracil; BAL: Bronchoalveolar lavage; CRP: C-reactive protein; CT: Computed tomography; ICU: Intensive care unit; ILD: Interstitial lung disease; IP: Interstitial pneumonia; IVIg: Intravenous immune globuline; OX: Oxaliplatin; PCR: Polymerase chain reaction; PEEP: Positive end expiratory pressure
Funding

Not applicable.

\section{Availability of data and materials}

The datasets supporting the conclusions of this article are included within the article.

\section{Authors' contributions}

ADW: treated the patient, drafted and designed the article, analyzed and interpreted the data. AD: provided the description of the pathology specimens and revised the manuscript critically for important intellectual content. AS: provided and interpreted the CT- images and revised the manuscript critically for important intellectual content. JP: provided data and revised the manuscript critically for important intellectual content. ML: provided the description of the pathology specimens and revised the manuscript critically for important intellectual content. PHJ: helped to draft the manuscript and the statistical analysis, revised the manuscript critically for important intellectual content. All authors read and approved the final manuscript.

Ethics approval and consent to participate

Not applicable.

\section{Consent for publication}

Written informed consent for publication was obtained from the patient described in the case report. A copy of the written consent is available for review by the Editor-in-Chief of the journal.

\section{Competing interests}

The authors declare that they have no competing interests.

\section{Publisher's Note}

Springer Nature remains neutral with regard to jurisdictional claims in published maps and institutional affiliations.

\section{Author details}

${ }^{1}$ Department of Intensive Care Medicine, Antwerp University Hospital, University of Antwerp, Wilrijkstraat 10, 2650 Edegem, Belgium. ${ }^{2}$ Department of Pathology, Antwerp University Hospital, University of Antwerp, Edegem, Belgium. ${ }^{3}$ Department of Radiology, Antwerp University Hospital, University of Antwerp, Edegem, Belgium. ${ }^{4}$ Department of Gastroenterology, Heilig Hart Hospital, Lier, Belgium.

Received: 14 July 2016 Accepted: 22 August 2017

Published online: 29 August 2017

References

1. Saltz L. Systemic therapy for metastatic colorectal cancer. Journal of the National Comprehensive Cancer Network : JNCCN. 2013;11:649-52.

2. Ocvirk J. Advances in the treatment of metastatic colorectal carcinoma. Radiol Oncol. 2009;43:1-8.

3. Chen ML, Fang $\mathrm{CH}$, Liang LS, Dai LH, Wang XK. A meta-analysis of chemotherapy regimen fluorouracil/leucovorin/oxaliplatin compared with fluorouracil/leucovorin in treating advanced colorectal cancer. Surg Oncol. 2010;19:38-45.

4. Gagnadoux F, Roiron C, Carrie E, Monnier-Cholley L, Lebeau B. Eosinophilic lung disease under chemotherapy with oxaliplatin for colorectal cancer. Am J Clin Oncol. 2002;25:388-90.

5. Hannan LM, Yoong J, Chong G, McDonald CF. Interstitial lung disease in a patient treated with oxaliplatin, 5-fluorouracil and leucovorin (FOLFOX) for metastatic colorectal cancer. Radiol Oncol. 2012;46:360-2.

6. Lim JH, Kim H, Choi WG, Lee MH. Interstitial lung disease associated with FOLFOX chemotherapy. J Cancer Res Ther. 2010;6:546-8.

7. Muneoka K, Shirai Y, Sasaki M, Wakai T, Sakata J, Hatakeyama K. Interstitial pneumonia arising in a patient treated with oxaliplatin, 5-fluorouracil, and, leucovorin (FOLFOX). Int J Clin Oncol. 2009;14:457-9.

8. Pasetto LM, Monfardini S. Is acute dyspnea related to oxaliplatin administration? World J Gastroenterol. 2006;12:5907-8.

9. Pena Alvarez C, Suh Oh HJ, Saenz de Miera Rodriguez A, Garcia Arroyo FR, Covela Rua M, Salgado Boquete L, et al. Interstitial lung disease associated with oxaliplatin: description of two cases. Clinical \& translational oncology : 
official publication of the Federation of Spanish Oncology Societies and of the National Cancer Institute of Mexico. 2009;11:332-3.

10. Arevalo Lobera S, Sagastibeltza Marinelarena N, Elejoste Echeberria I, Mele Olive M, Egana Otano L, Basterretxea Badiola L, et al. Fatal pneumonitis induced by oxaliplatin. Clinical \& translational oncology : official publication of the Federation of Spanish Oncology Societies and of the National Cancer Institute of Mexico. 2008;10:764-7.

11. Jung KH, Kil SY, Choi IK, Seo JH, Shin C, Kim YS, et al. Interstitial lung diseases in patients treated with oxaliplatin, 5-fluorouracil and leucovorin (FOLFOX). Int J Tuberc Lung Dis. 2006;10:1181-2.

12. Prochilo T, Abeni C, Bertocchi P, Zaniboni A. Oxaliplatin-induced lung toxicity. Case report and review of the literature. Curr Drug Saf. 2012;7:179-82.

13. Shogbon AO, Hap J, Dretler R, Dalvi AG. Cryptogenic organizing pneumonia during adjuvant chemotherapy with oxaliplatin, 5-fluorouracil, and leucovorin (FOLFOX) for colon cancer. J Pharm Pract. 2013;26:62-6.

14. Wildner $D$, Boxberger $F$, Wein $A$, Wolff $K$, Albrecht $H$, Mannlein $G$, et al. Granulomatous lung disease requiring mechanical ventilation induced by a single application of oxaliplatin-based chemotherapy for colorectal cancer: a case report. Case reports in oncological medicine. 2013;2013:683948.

15. Shimura T, Fuse N, Yoshino T, Minashi K, Tahara M, Doi T, et al. Clinical features of interstitial lung disease induced by standard chemotherapy (FOLFOX or FOLFIRI) for colorectal cancer. Ann Oncol 2010;21:2005-10.

16. Dahlqvist C, Fremault A, Carrasco J, Colinet B. Obliterative bronchiolitis with organising pneumonia following FOLFOX 4 chemotherapy. Rev Mal Respir. 2010:27:84-7.

17. Garrido M, O'Brien A, Gonzalez S, Clavero JM, Orellana E. Cryptogenic organizing pneumonitis during oxaliplatin chemotherapy for colorectal cancer: case report. Chest. 2007;132:1997-9.

18. Homma T, Kurokawa M, Yamamoto Y, Matsukura S, leki K, Suzuki S, et al. Oxaliplatin-induced lung injury with allergic reaction. Chinese journal of cancer research = Chung-kuo yen cheng yen chiu. 2011;23:232-5.

19. Ohori H, Takahashi M, Ogasawara N, Suzuki M, Miyate Y, Kato S. Two cases of interstitial lung diseases in patients treated with oxaliplatin, 5-fluorouracil and Leucovorin (FOLFOX). Gan To Kagaku Ryoho. 2009:36:295-8.

20. Meyer KC. The role of bronchoalveolar lavage in interstitial lung disease. Clin Chest Med. 2004;25:637-49. v

21. Limper AH. Chemotherapy-induced lung disease. Clin Chest Med. 2004;25:53-64.

22. Krause I, Shoenfeld Y. Intravenous immunoglobulin treatment for fibrosis, atherosclerosis, and malignant conditions. Methods in molecular medicine. 2005;109:403-8.

23. Molina V, Blank M, Shoenfeld Y. Intravenous immunoglobulin and fibrosis. Clin Rev Allergy Immunol. 2005;29:321-6.

24. Molina V, Haj-Yahia S, Solodeev I, Levy Y, Blank M, Shoenfeld Y. Immunomodulation of experimental pulmonary fibrosis by intravenous immunoglobulin (IVIG). Autoimmunity. 2006;39:711-7.

25. Basyigit I, Onyilmaz TA, Boyaci H, Temiz S, Inan N, Baris SA, et al. Interstitial pneumonitis associated with FOLFOX-6 chemotherapy. Translational Medicine. 2014;4

26. Choi JH, Shin JA, Park HK, Kim SY, Jung H, Lee SS, et al. Sarcoidosis associated with oxaliplatin-based chemotherapy for colorectal cancer. Case reports in oncological medicine. 2014;2014:203027.

27. Ishizone S, Koide N, Akita N, Karasawa F, Kobayashi N, Koizumi T, et al. Fatal interstitial pneumonia associated with oxaliplatin-based therapy in a patient with metastatic rectal cancer. Clin J Gastroenterol. 2011;4:157-61.

28. Lee EJ, Lee SY, In KH, Kim CH, Park S. Organizing pneumonia associated with oxaliplatin-combined chemotherapy: a case report. Med Princ Pract. 2012;21:89-92

29. Mundt P, Mochmann HC, Ebhardt H, Zeitz M, Duchmann R, Pauschinger M. Pulmonary fibrosis after chemotherapy with oxaliplatin and 5 -fluorouracil for colorectal cancer. Oncology. 2007;73:270-2.

30. Park S, Jung JJ, Kim GB, Yoon HS, Ko SH, Ko JE, et al. Interstitial lung disease associated with combination chemotherapy of oxaliplatin, 5-fluorouracil, and leucovorin. Korean J Gastroenterol. 2010;55:340-3.

31. Piccolo D, Feeney KT, Tribe AE, Thompson PJ, Millward MJ, van Hazel GA. Oxaliplatin-induced interstitial lung disease. Asia-Pacific Journal of Clinical Oncology. 2008:4:175-80.

32. Pontes LB, Armentano DP, Soares A, Gansl RC. Fatal pneumonitis induced by oxaliplatin: description of three cases. Case reports in oncology. 2012;5:104-9.

33. Ruiz-Casado A, Garcia MD, Racionero MA. Pulmonary toxicity of 5-fluoracil and oxaliplatin. Clinical \& translational oncology : official publication of the
Federation of Spanish Oncology Societies and of the National Cancer Institute of Mexico. 2006;8:624.

34. Ryu CG, Jung EJ, Kim G, Kim SR, Hwang DY. Oxaliplatin-induced Pulmonary Fibrosis: Two Case Reports. Journal of the Korean Society of Coloproctology. 2011;27:266-9.

35. Soon WC, West K, Gibeon D, Bowen EF. Pulmonary Fibrosis Secondary to FOLFOX Chemotherapy: A Case Report. Case reports in oncology. 2014;7:662-8.

36. Trisolini R, Lazzari Agli L, Tassinari D, Rondelli D, Cancellieri A, Patelli M, et al. Acute lung injury associated with 5-fluorouracil and oxaliplatinum combined chemotherapy. Eur Respir J. 2001;18:243-5.

37. Watkins J, Slade JH, Phan A, Eng C, Weissferdt A, Overman MJ. Fatal diffuse alveolar damage associated with oxaliplatin administration. Clin Colorectal Cancer. 2011;10:198-202.

38. Wilcox BE, Ryu JH, Kalra S. Exacerbation of pre-existing interstitial lung disease after oxaliplatin therapy: a report of three cases. Respir Med. 2008; 102:273-9.

39. Yague $\mathrm{XH}$, Soy E, Merino $\mathrm{BQ}$, Puig J, Fabregat MB, Colomer R. Interstitial pneumonitis after oxaliplatin treatment in colorectal cancer. Clinical \& translational oncology : official publication of the Federation of Spanish Oncology Societies and of the National Cancer Institute of Mexico. 2005;7:515-7.

40. Abotchie PN, Vernon SW, Du XL. Gender differences in colorectal cancer incidence in the United States, 1975-2006. J Women's Health (Larchmt). 2012;21:393-400.

41. Brenner H, Rothenbacher D, Arndt V. Epidemiology of stomach cancer. Methods Mol Biol. 2009:472:467-77.

42. Wu CY, Lin JT. The changing epidemiology of Asian digestive cancers: From etiologies and incidences to preventive strategies. Best Pract Res Clin Gastroenterol. 2015;29:843-53.

43. Wiela-Hojenska A, Kowalska T, Filipczyk-Cisarz E, Lapinski L, Nartowski K. Evaluation of the toxicity of anticancer chemotherapy in patients with colon cancer. Adv Clin Exp Med. 2015;24:103-11.

44. Schmetzer O, Florcken A. Sex differences in the drug therapy for oncologic diseases. Handb Exp Pharmacol. 2012:411-42.

45. Ferguson EC, Berkowitz EA. Lung CT: Part 2, The interstitial pneumoniasclinical, histologic, and CT manifestations. AJR Am J Roentgenol. 2012;199: W464-76.

46. Ryu JH, Daniels CE, Hartman TE, Yi ES. Diagnosis of interstitial lung diseases. Mayo Clin Proc. 2007;82:976-86.

47. Camus P, Fanton A, Bonniaud P, Camus C, Foucher P. Interstitial lung disease induced by drugs and radiation. Respiration; international review of thoracic diseases. 2004;71:301-26.

48. Alter P, Herzum M, Soufi M, Schaefer JR, Maisch B. Cardiotoxicity of 5fluorouracil. Cardiovasc Hematol Agents Med Chem. 2006:4:1-5.

49. Mosseri M, Fingert HJ, Varticovski L, Chokshi S, Isner JM. In vitro evidence that myocardial ischemia resulting from 5 -fluorouracil chemotherapy is due to protein kinase C-mediated vasoconstriction of vascular smooth muscle. Cancer Res. 1993;53:3028-33.

50. Andou H, Itoh K, Tsuda T. A case of fluorouracil-induced pneumonitis. Nihon Kyobu Shikkan Gakkai Zasshi. 1997;35:1080-3.

51. Raymond E, Faivre S, Chaney S, Woynarowski J, Cvitkovic E. Cellular and molecular pharmacology of oxaliplatin. Mol Cancer Ther. 2002;1:227-35.

52. Raymond E, Chaney SG, Taamma A, Cvitkovic E. Oxaliplatin: a review of preclinical and clinical studies. Ann Oncol. 1998;9:1053-71.

53. Vietor NO, George BJ. Oxaliplatin-induced hepatocellular injury and ototoxicity: a review of the literature and report of unusual side effects of a commonly used chemotherapeutic agent. J Oncol Pharm Pract. 2012;18:355-9.

54. Amemiya K, Semino-Mora C, Granger RP, Dalakas MC. Downregulation of TGF-beta1 mRNA and protein in the muscles of patients with inflammatory myopathies after treatment with high-dose intravenous immunoglobulin. Clin Immunol. 2000;94:99-104.

55. Fouque A, Debure L, Legembre P. The CD95/CD95L signaling pathway: a role in carcinogenesis. Biochim Biophys Acta. 1846;2014:130-41.

56. Ge Y, Peng Q, Zhang S, Zhou H, Lu X, Wang G. Cyclophosphamide treatment for idiopathic inflammatory myopathies and related interstitial lung disease: a systematic review. Clin Rheumatol. 2015;34:99-105.

57. Burz C, Berindan-Neagoe IB, Balacescu O, Tanaselia C, Ursu M, Gog A, et al. Clinical and pharmacokinetics study of oxaliplatin in colon cancer patients. Journal of gastrointestinal and liver diseases: JGLD. 2009;18: 39-43. 